\title{
Fondaparinux vs warfarin for the treatment of unsuspected pulmonary embolism in cancer patients
}

\author{
Hikmat Abdel-Razeq' \\ Asem Mansour ${ }^{2}$ \\ 'Department of Internal Medicine, \\ 2Department of Radiology, King \\ Hussein Cancer Center, Amman, \\ Jordan
}

\author{
This article was published in the following Dove Press journal: \\ Drug Design, Development and Therapy \\ 24 August 2016 \\ Number of times this article has been viewed
}

\section{Dear editor}

We read with great interest the study published on June 23, 2016 by Amato et al entitled "Fondaparinux vs warfarin for the treatment of unsuspected pulmonary embolism in cancer patients." While we value the importance of this study in highlighting this important topic, we have several issues to be addressed.

Venous thromboembolisms (VTEs), especially pulmonary embolism (PE), in asymptomatic patients are well-described clinical entities that are usually underrecognized. It is believed that most fatal PEs are not suspected clinically and are not treated. ${ }^{2,3}$ This issue is even more important in cancer patients where respiratory symptoms can often be attributed to the cancer itself or its treatment.

We fully agree with the authors that incidental, or unsuspected PE, is not a benign diagnosis especially in cancer patients. We previously reported our experience in 34 incidental PEs in such patients. ${ }^{4}$ Except for five (15\%), all other patients were anticoagulated; all with low-molecular-weight heparin (LMWH). With follow-up, two patients developed recurrent PE, two others had clinical and echocardiographic evidence of pulmonary hypertension, and nine (26\%) died suddenly within 30 days of the diagnosis of PE; two of these were among the five patients who were not anticoagulated.

In their introduction, the authors stated that "Warfarin is commonly used prophylactically in patients with a high risk of thromboembolic events." This statement is not accurate as warfarin is not used for VTE prophylaxis. We assume that the authors meant active treatment (not prophylaxis) of VTE.

Also, the authors stated that "Fondaparinux, is the newest agent with venous thromboembolism (VTE) prophylaxis activity" and this statement is not accurate, either. Fondaparinux, which was introduced and approved initially for VTE prophylaxis then for active treatment of both deep vein thrombosis and PE for over 15 years now, is not new anymore. 5,6 The "relatively new" oral anticoagulants, the direct thrombin inhibitors (dabigatran) and the direct factor Xa inhibitors (rivaroxaban, apixaban, and edoxaban), are the most recently introduced anticoagulants in clinical practice. ${ }^{7,8}$

The authors clearly stated that asymptomatic PE should be treated the same way symptomatic PE is treated; a statement that is fully supported by many published guidelines, including the American College of Chest Physicians. ${ }^{9}$ The authors also stated, based at least on the CLOT trial, ${ }^{10}$ that LMWH (dalteparin) is superior to warfarin. Yet, the authors used warfarin, not LMWH, to compare fondaparinux with.
Correspondence: Hikmat Abdel-Razeq Department of Internal Medicine, King Hussein Cancer Center, 202 Queen Rania Al Abdullah Street, Amman, I I 94 I Jordan

Tel +96265300460 ext 1000 Email habdelrazeq@khcc.jo
Drug Design, Development and Therapy 2016:10 2677-2679

(c) (7) (ㅇ) 2016 Abdel-Razeq and Mansour. This work is published and licensed by Dove Medical Press Limited. The full terms of this license are available at https://www.dovepress.com/terms.php cC) and incorporate the Creative Commons Attribution - Non Commercial (unported, v3.0) License (http://creativecommons.org/licenses/by-nc/3.0/). By accessing the work you hereby accept the Terms. Non-commercial uses of the work are permitted without any further permission from Dove Medical Press Limited, provided the work is properly attributed. For permission for commercial use of this work, please see paragraphs 4.2 and 5 of our Terms (https://www.dovepress.com/terms.php). 
Though we agree with the authors that the recently published CATCH trial failed to show superiority of LMWH (tinzaparin) over warfarin in this setting, ${ }^{11}$ however, due to many factors addressed by the authors in their paper, LMWHs are still the preferred agents for active VTE treatment in cancer patients.

Additionally, the CATCH study showed that tinzaparin significantly reduced the risk of clinically relevant nonmajor bleeding compared with warfarin. Together with the adverse events data, $\mathrm{CATCH}$ demonstrated that tinzaparin, even when given at a full therapeutic dose for up to 6 months, is a safe and convenient drug in cancer patients. It should also be noted that the $\mathrm{CATCH}$ study results were published after enrolling all patients in the current study under discussion.

More recently, our group participated in a pooled analysis of 926 cancer patients from eleven cohorts, all with incidental PE. While VTE recurrence risk was comparable under LMWH and warfarin $(6.2 \%$ vs $6.4 \%$; hazard ratio $0.9 ; 95 \%$ confidence interval 0.3-3.1), the risk of major hemorrhage was higher under warfarin than under LMWH (13\% vs 3.9\%; hazard ratio $3.9 ; 95 \%$ confidence interval $1.6-10) .{ }^{12}$

We believe that the era of having warfarin as a drug to compare new anticoagulants within clinical trials, in cancer patients, is not attractive anymore. Researchers are moving forward, comparing the new oral anticoagulants, such as rivaroxaban versus LMWH, in a huge research program called the "CALLISTO". This program is evaluating cancer patient populations being treated for VTEs or at high risk for developing them. Such a program will encompass the field of cancer-associated thrombosis through nine studies, including seven clinical trials and two registries across various cancer types, in $>4,000$ patients globally. ${ }^{13}$

Fondaparinux, on the other hand, has a major advantage over all other heparins, including LMWH. Being a small molecule with just five sugars (pentasaccharide), it is rarely associated with thrombocytopenia, thus allowing its clinical use in the treatment of heparin-induced thrombocytopenia. ${ }^{14}$

In conclusion, we want to congratulate the authors for addressing such an important topic, but we believe that such a study would have a better impact if the authors chose one of the LMWHs to compare fondaparinux with. The real excitement in antithrombotic therapy in cancer patients will be the introduction of oral direct thrombin and anti-Xa inhibitors.

\section{Disclosure}

The authors report no conflicts of interest in this communication.

\section{References}

1. Amato B, Compagna R, Rocca A, et al. Fondaparinux vs warfarin for the treatment of unsuspected pulmonary embolism in cancer patients. Drug Des Devel Ther. 2016;10:2041-2046.

2. Ryu JH, Olson EJ, Pellikka PA. Clinical recognition of pulmonary embolism: problem of unrecognized and asymptomatic cases. Mayo Clin Proc. 1998;73(9):873-879.

3. Pineda LA, Hathwar VS, Grant BJ. Clinical suspicion of fatal pulmonary embolism. Chest. 2001;120(3):791-795.

4. Abdel-Razeq H, Mansour A, Ismael Y. Incidental pulmonary embolism in cancer patients: clinical characteristics and outcome: a comprehensive cancer center experience. Vasc Health Risk Manag. 2011;7: 153-158.

5. Büller HR, Davidson BL, Decousus H, et al; Matisse Investigators. Fondaparinux or enoxaparin for the initial treatment of symptomatic deep venous thrombosis: a randomized trial. Ann Intern Med. 2004; 140(11):867-873.

6. Büller HR, Davidson BL, Decousus H, et al; Matisse Investigators. Subcutaneous fondaparinux versus intravenous unfractionated heparin in the initial treatment of pulmonary embolism. $N$ Engl J Med. 2003; 349(18):1695-1702.

7. Robertson L, Kesteven P. Oral direct thrombin inhibitors or oral factor Xa inhibitors for the treatment of deep vein thrombosis [Cochrane Protocol]. PROSPERO 2015:CRD42015017423. Available from: http://www.crd.york.ac.uk/PROSPERO/display_record. asp?ID=CRD42015017423. Accessed 25 June 2016.

8. Bauer K. Pros and cons of new oral anticoagulants. Hematology Am Soc Hematol Educ Program. 2013;2013:464-470.

9. Kearon C, Akl EA, Comerota AJ, et al; American College of Chest Physicians. Antithrombotic therapy for VTE disease: antithrombotic therapy and prevention of thrombosis, 9th ed: American College of Chest Physicians evidence-based clinical practice guidelines. Chest. 2012;141(Suppl 2):e419S-e494S.

10. Lee AY, Levine MN, Baker RI, et al. Low-molecular-weight heparin versus a coumarin for the prevention of recurrent venous thromboembolism in patients with cancer. N Engl J Med. 2003;349(2): $146-153$.

11. Lee AY, Kamphuisen PW, Meyer G, et al; CATCH Investigators. Tinzaparin vs warfarin for treatment of acute venous thromboembolism in patients with active cancer: a randomized clinical trial. JAMA. 2015;314(7):677-686.

12. Van der Hulle T, den Exter PL, Planquette B, et al. Risk of recurrent venous thromboembolism and major hemorrhage in cancer-associated incidental pulmonary embolism among treated and untreated patients: a pooled analysis of 926 patients. J Thromb Haemost. 2016;14(1):105-113.

13. Available from: http://www.jnj.com/news/all/New-ClinicalResearch-Program-Initiated-for-the-Prevention-and-Treatment-ofLife-Threatening-Blood-Clots-in-Patients-with-Cancer. Accessed June 25, 2016.

14. Abdel-Razeq H, Ismael Y. Dealing with thrombocytopenia during anticoagulation with heparins for active venous thromboembolism. A play-it-safe practical approach! Ther Clin Risk Manag. 2011;7: 213-217. 


\section{Authors' reply \\ Bruno Amato ${ }^{1,2}$ \\ Rita Compagna ${ }^{1,2}$ \\ Aldo Rocca ${ }^{2}$ \\ Tommaso Bianco² \\ Marco Milone ${ }^{2}$ \\ Luigi Sivero \\ Gabriele Vigliotti ${ }^{2}$ \\ Maurizio Amato ${ }^{2}$ \\ Michele Danzi ${ }^{2}$ \\ Giovanni Aprea² \\ Luca Gallelli ${ }^{3}$ \\ Stefano de Franciscis ${ }^{1,4}$ \\ Raffaele Serra ${ }^{1,4}$ \\ 'Interuniversity Center of Phlebolymphology (CIFL), International Research and Educational Program in Clinical and Experimental Biotechnology, University Magna Graecia of Catanzaro, Viale \\ Europa, Catanzaro, ${ }^{2}$ Department of Clinical Medicine and Surgery, University of Naples "Federico II", Naples, ${ }^{3}$ Department of Health Sciences, ${ }^{4}$ Department of Medical and Surgical Sciences, University of Catanzaro, Catanzaro, Italy}

Correspondence: Raffaele Serra

Department of Medical and Surgical Sciences, University

of Catanzaro, Viale Europa, Catanzaro 88I00, Italy

Tel +39 96I 3647380

Email rserra@unicz.it

\section{Dear editor}

We appreciate the interest and the well-advised comments on our paper ${ }^{1}$ and we thank the authors of the letter to the editor for the opportunity to clarify briefly some aspects of our paper.
First of all, we used the term "prophylaxis" meaning "secondary prevention", and therefore as a synonym of "treatment", but we agree that the word "treatment" would be more appropriate.

We agree with the authors of the letter - fondaparinux is an old agent approved by European Medicines Agency in 2002 and marketed in Italy from 2003. However, it has been the last one after LMWH was approved, and therefore we used the term "newest agent".

Finally, we fully agree with the authors' statement: "The real excitement in antithrombotic therapy in cancer patients will be the introduction of oral direct thrombin and anti-Xa inhibitors". In fact, we think that these "relatively new" oral anticoagulants may represent a clinical benefit in these patients.

However, to date, no clinical trials in cancer patients have been performed, even if recently Schulman et al, ${ }^{2}$ reviewing the literature data in six clinical trials, suggest that directacting oral anticoagulants have a good safety profile with respect to warfarin in cancer patients.

\section{Disclosure}

The authors report no conflicts of interest in this work.

\section{References}

1. Amato B, Compagna R, Rocca A, et al. Fondaparinux vs warfarin for the treatment of unsuspected pulmonary embolism in cancer patients. Drug Des Devel Ther. 2016;10:2041-2046.

2. Schulman S, Shrum J, Majeed A. Management of bleeding complications in patients with cancer on DOACs. Thromb Res. 2016;140(Suppl 1): S142-S147.

Dove Medical Press encourages responsible, free and frank academic debate. The content of the Drug Design, Development and Therapy 'letters to the editor' section does not necessarily represent the views of Dove Medical Press, its officers, agents, employees, related entities or the Drug Design, Development and Therapy editors. While all reasonable steps have been taken to confirm the content of each letter, Dove Medical Press accepts no liability in respect of the content of any letter, nor is it responsible for the content and accuracy of any letter to the editor.

\section{Publish your work in this journal}

Drug Design, Development and Therapy is an international, peerreviewed open-access journal that spans the spectrum of drug design and development through to clinical applications. Clinical outcomes, patient safety, and programs for the development and effective, safe, and sustained use of medicines are a feature of the journal, which has also been accepted for indexing on PubMed Central. The manuscript management system is completely online and includes a very quick and fair peer-review system, which is all easy to use. Visit http://www.dovepress.com/testimonials.php to read real quotes from published authors.

Submit your manuscript here: http://www.dovepress.com/drug-design-development-and-therapy-journal 